\title{
Penerapan Kontrol Logika Fuzzy pada Sistem Pengering Irisan Kripik Singkong
}

\author{
Suhariningsih, Renny Rakhmawati
}

Politeknik Elektronika Negeri Surabaya

Surabaya, Indonesia

nuning@pens.ac.id, renny@pens.ac.id

\begin{abstract}
Abstrak
Indonesia dikenal memiliki beragam kuliner yang bahan dasarnya memanfaatkan hasil bumi sendiri, salah satu kuliner Indonesia yang terkenal adalah keripik singkong.Bahan dasar yang harganya murah dansangat gampang dicari sehinggabanyak ditemukan di sebagian besar wilayah Indonesia.Itu sebabnya banyak Usaha Kecil Menengah (UKM) yang memproduksi makanan kecil ini. Proses produksi dilakukan secara konvensional, dimulai dari proses pengupasan, pembersihan, pemotongan tipis-tipis, pengeringan, lalu penggorengan.

Proses pengeringan dilakukan dengan menaruh di tempat terbuka, di bawah sinar matahari langsung sehingga menyebabkan proses pengeringan membutuhkan waktu yang relatif lama. Hal ini akanmemperlambat proses produksi, menyebabkan tumbuhnya jamur, sehingga menjadikan rasa keripik agak berbau tidak enak, tampilan juga menjadi kurang menarik sehingga menguranginilau jual.

Pada penelitian ini didesain suatu sistem pengeringan irisan keripik singkong dengan kontrol logika fuzzy, dalam ruang yang bersih, tertutup dan temperatur yang stabil sehingga menjadi relatif lebih cepat kering. $\mathrm{Hal}$ ini dapat mengurangi potensi tumbuhnya jamur, tidak berbau dan tampilan lebih bersih/menarik, lebih hygiene. Dengan demikian dapat meningkatkan produksi dan menjadi lebih disukai oleh konsumen sehingga nilai jualnya menjadi meningkat.
\end{abstract}

Pada sistem ini digunakan rangkaian $A C$ to $A C$ Voltage Controller untuk mengontrol agar suhu ruang pengering stabil pada suhu set point $70^{\circ} \mathrm{C}$ dan lebih cepat menuju set point,yang diproses menggunakan kontrol logika Fuzzydengan mengimplementasikan padamikrokontroller ARM STM32F4VG Discovery.

Kata kunci : Ac to Ac Voltage Controller, Logika Fuzzy, Singkong

\section{Pendahuluan}

Indonesia adalah negara yang sangat kaya akan seni, budaya, hasil alam dll maka pemerintah sedang menggalakkan penggalian potensi kekayaan tersebut disesuaikan dengan daerah masing-masing. Penggalian kekayaan lokal ini diharapkan dapat menciptakan lapangan kerja sehingga mengurangi angka pengangguran dan kemiskinan. Dengan demikian mampu meningkatkan penghasilan perorangan, meningkatkan pendapatan

Gambar 2.1. Rangkaian kontrol tegangan dengan menggunakan Triac. daerah, yang dampaknya dapat meningkatkan pendapatan nasional.

Indonesia dikenal memiliki beragam kuliner yang bahan dasarnya memanfaatkan hasil bumi sendiri, salah satu kuliner Indonesia yang terkenal adalah suatu makanan kecil berupa keripik singkong. Bahan dasar dari makanan ini adalah singkong, yang harganya murah dansangat gampang dicari karena hampir dapat tumbuh di seluruh wilayah Indonesia sehingga makanan kecil ini jg banyak ditemukan di sebagian besar wilayah Indonesia. Itu sebabnya banyak UKM yang memproduksi makanan kecil ini. Proses produksi makanan kecil ini masih banyak dilakukan secara konvensional. Dimulai dari proses pengupasan, pembersihan, pemotongan tipis-tipis kemudian dilakukan proses pengeringan, lalu penggorengan. Proses pengeringan dilakukan dengan menaruh di tempat terbukasehingga tidak hygiene. Singkong dikeringkan di bawah sinar matahari sehingga sangat tergantung pada cuaca. Hal ini menyebabkan proses pengeringan membutuhkan waktu yang relatif lama sehingga selain memperlambat proses produksi, juga sering menyebabkan tumbuhnya jamur, yang menjadikan rasa keripik menjadi kurang renyah, agak berbau tidak enak(agak apek), tampilan juga menjadi kurang menarik sehingga menguranginilau jual.

\section{Diskusi}

\subsection{AC to AC Voltage Controller}

Dalam system ini untuk mengkontrol tegangan AC menggunakan metode kontrol tegangan, Pada metode kontrol ini tegangan akan bekerja dengan meredam bagian dari gelombang sinusoidal setiap setengah periode atau satu periode penuh. Adapun rangkaian kontrol tegangan dengan TRIAC atau sepasang thyristor yang dipasang secara berlawanan arah seperti terlihat pada gambar 2.1berikut :

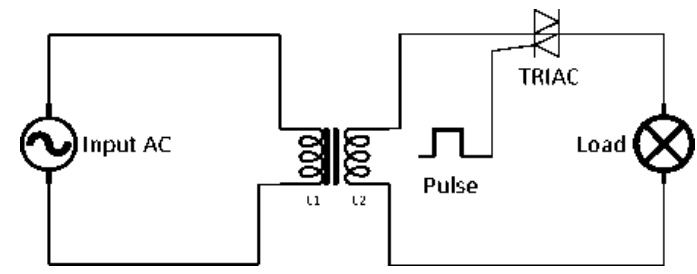


Kondisi TRIAC terbuka atau tertutup tergantung pada penyulutan dari gate driver. TRIAC akan pada kondisi terbuka jika gate pada TRIAC tidak mendapatkan penyulutan, pada kondisi ini terdapat bagian dari gelombang sinus yang teredam sepanjang beberapa derajat. Adapun tegangan output dari rangkaian $A C$ to $A C$ Voltage Controllerdapat $t$ dihitung menggunakan persamaan 1.

Vorms $=V s \sqrt{\frac{1}{\pi}(\pi-\alpha)+\frac{\sin (2 \alpha)}{2}}$

Adapun bentuk gelombang keluaran dari rangkaian seperti terlihat pada Gambar 2.2 dengan penjelasan : jika gate pada komponen TRIAC mendapatkan penyulutan, maka TRIAC pada kondisi tertutup sesuai besarnya firing angle yang diberikan, sehingga pada kondisi ini gelombang sinus dapat muncul namun tidak secara penuh dan jika dilihat dari gelombang sinusoidalnya.

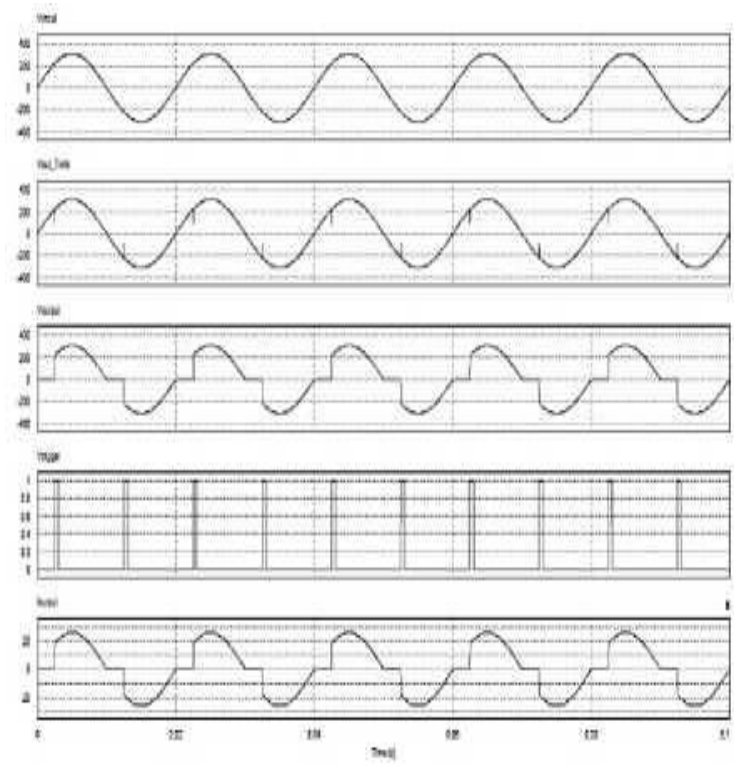

Gambar 2.2.Gelombang sinus sistem

\subsection{Fuzzy Logic Control}

Kontrol logika fuzzy berarti kontrol terbuka dan loop tertutup dari proses teknis yang dapat dilihat dari gambar 3 blok diagram kontrol logika fuzzy, termasuk pengolahan nilai yang terukur, berasal dari variabel terukur, dan set point. Variabel keluaran dalam bentuk variabel pengoreksi. Transformasi harus dilakukan antara masukan dan variabel keluaran dari proses dan dunia fuzzy (fuzzifikasi, defuzzifikasi) komponen inti pengendalian fuzzy terdiri dari linguistic aturan dasar (rule base) dan kesimpulan (inference).

Seperti diketahui bahwa logika fuzzy adalah peningkatan dari logika booleanyang berhadapan dengan konsep kebenaran sebagian. Dimana logika klasik menyatakan bahwa segala hal dapat diekspresikan dalam istilah binery (0 atau 1, ya atau tidak), logika fuzzy menggantikan kebenaran booleandengan tingkat kebenaran.

\section{$3 \quad$ Metodologi}

Alat pengering irisan kripik singkong pada system ini dikontrol dengan suhu set point $70^{\circ} \mathrm{C}$ menggunakan metode kontrol logika fuzzy pada ruang pengering yang tertutup. Secara keseluruhan sistem dapat digambarkan seperti diagram blok Gambar 3.1 berikut :

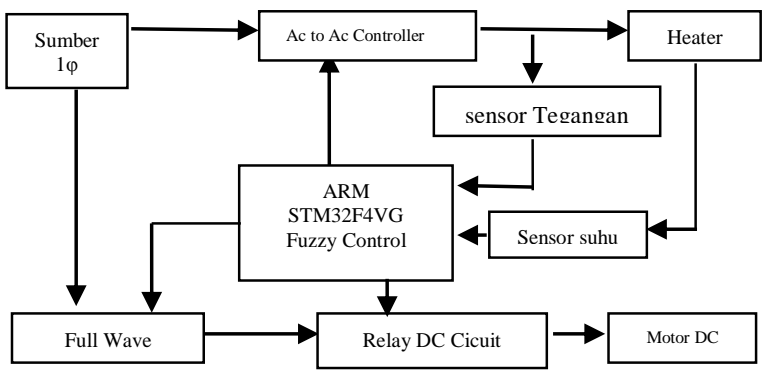

\section{Gambar 3.1Diagram Blok Sistem}

Sebagai pengontrol tegangan keluaran pada heater guna pengoptimalan suhu pada ruang pengering digunakan perangkat $A C$ to $A C$ Voltage Controller, IC TCA 785 dan DAC (Digital to Analog Converter).Sensor suhu SHT11 yang terpasang pada ruang pengering sebagai umpan balik pada sistem kontrol suhu agar tetap sesuai dengan set point yang dibutuhkan.

\subsection{Perancangan AC to AC Voltage Controller}

Adapun Rangkauian Ac to Ac Voltage Controller adalah seperti pada Gambar 3.2 dialpikasikan diaplikasikan pada plan menggunakan komponen TRIAC BTA 41 yang mampu bekerja hingga arus maksimal 40 Ampereserta tegangan hingga 600 Volt AC .

Pengaturan tegangan AC pada beban yang berupa heater pada plan menggunakan komponen TRIAC. Kaki gate pada komponen TRIAC merupakan suatu titik tempat pengontrolan penyulutan yang akan dilakukan oleh TRIAC itu sendiri. Pulsa keluaran yang dibangkitan dari rangkaian IC TCA 785 akan diinjeksikan ke kaki gate pada TRIAC.

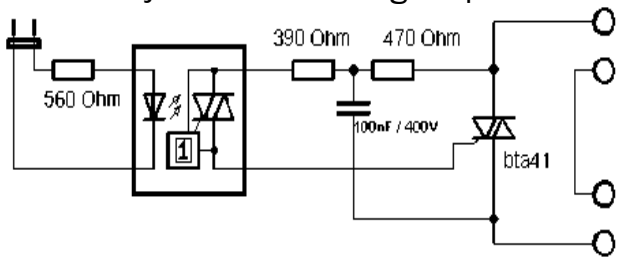

Gambar 3.2.SchematicRangkaianAC to AC Voltage Controller.

Kapasitor pada rangkaian digunakan agar 
dapat meredam efek gangguan arus yang dihasilkan karena proses switching pada TRIAC.

\subsection{Perancangan Fuzzy Logic Control}

Untuk kontrol tegangan keluaran $A C$ to $A C$ Voltage Controller pada sistenm ini dirancang control logika fuzzy yang berfungsi sebagai sistem kontrol DAC pada mikrokontroler. Kontrol tegangan ini digunakan untuk mempertahankan suhu dalam ruang pengering. Kontrol logika fuzzy yang digunakan adalah menggunakan metode Sugeno dengan rule base $5 \times 5$, dimana keluaran sistem tidak berupa himpunan fuzzy, tetapi berupa konstanta atau persamaan linier.

Keluaran dari kontrol logika fuzzy berasal dari konversi pembacaan sensor suhu berupa SHT11 yang kemudian diubah dalam derajat keanggotaan pada fungsi keanggotaan error dan delta error. Keluaran kontrol logika fuzzy adalah mengatur besarnya Digital to Analog Converter(DAC) pada mikrokontroler untuk switching TRIAC pada rangkaian AC to AC Voltage Controller.

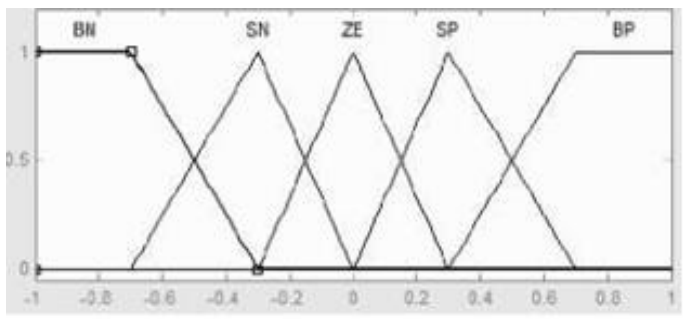

Gambar 3.3 Fungsi keanggotaan input error.

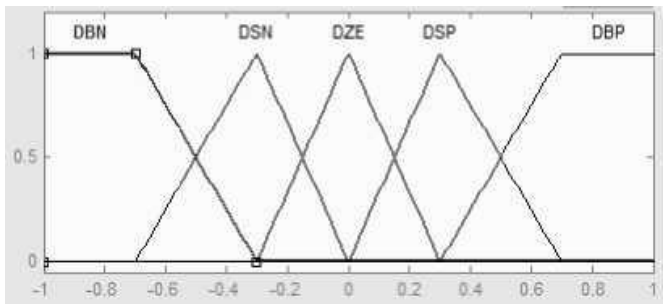

Gambar 3.4.Fungsi keanggotaan input delta error.

Adapun rancangan fuzzyfikasi dengan fungsi keanggotaan gabungan segitiga dan trapesium dapat dilihat pada Gambar 3.3 dan Gambar 3.4.

Adapun Tabel 3.1 merupakan aturan (rule base) untuk kontrol logika fuzzy system yang dibuat berdasar kedua fungsi keanggotaan error dan $\Delta$ error tersebut di atas.

Tabel 3.1 Rule base fuzzy $5 \times 5$.

\begin{tabular}{|c|c|c|c|c|c|}
\hline Error & \multirow{2}{*}{$\mathrm{BN}$} & $\mathrm{SN}$ & $\mathrm{ZE}$ & $\mathrm{SP}$ & $\mathrm{BP}$ \\
\hline Delta error & & & & & \\
\hline $\mathrm{DBN}$ & $\mathrm{kbs}$ & $\mathrm{kbs}$ & $\mathrm{kb}$ & $\mathrm{k}$ & $\mathrm{bs}$ \\
\hline $\mathrm{DSN}$ & $\mathrm{kbs}$ & $\mathrm{kb}$ & $\mathrm{k}$ & $\mathrm{bs}$ & $\mathrm{t}$ \\
\hline
\end{tabular}

\begin{tabular}{|c|c|c|c|c|c|}
\hline DZE & $\mathrm{kb}$ & $\mathrm{k}$ & $\mathrm{bs}$ & $\mathrm{t}$ & $\mathrm{tb}$ \\
\hline $\mathrm{DSP}$ & $\mathrm{k}$ & $\mathrm{bs}$ & $\mathrm{T}$ & $\mathrm{tb}$ & $\mathrm{tbs}$ \\
\hline $\mathrm{DBP}$ & $\mathrm{bs}$ & $\mathrm{T}$ & $\mathrm{tb}$ & $\mathrm{tbs}$ & $\mathrm{tbs}$ \\
\hline
\end{tabular}

Defuzzyfikasi (output) dari kontrol logika fuzzy ini berupa singleton, seperti ditunjukkan pada Gambar 3.5.

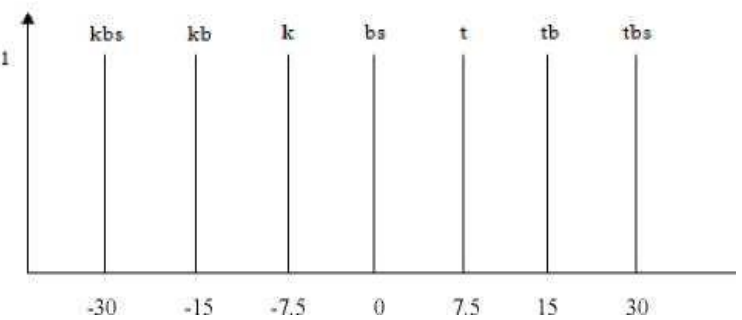

Gambar 3.5.Fungsi keanggotaan output(singleton).

Proses defuzzyfikasi yang digunakan pada metode sugeno yaitu menggunakan Wieghted Average.

$$
\text { Defuzzy }=\frac{\sum_{n=i}^{n} \mathrm{w}_{\mathrm{i}} \mathrm{z}_{\mathrm{i}}}{\sum_{n=i}^{n} \mathbf{W}_{\mathrm{i}}}
$$

\section{Pengujian dan Pembahasan}

Bab ini dimaksudkan untuk mengetahui kinerja system sebagai berikut :

\subsection{AC to AC Voltage Controller}

Pengaturan temperatur pada ruang pengering dilakukan dengan mengatur besarnya tegangan yang masuk ke heater. Sedangkan rangkaian $A C$ to AC Voltage Controllerdapat digunakan untuk mengatur besarnya tegangan yang menuju beban, yaitu sebagai tegangan masukan beban. Gambar 4.1 merupakan data hasil pengujian dari rangkaian Ac to Ac Voltage Controller yang menunjukkan nilai tegangan masukan, tegangan keluaran, serta perhitungan tegangan keluaran teori dan tegangan keluaran pada simulasi.

Tegangan keluaran rangkaian AC to Ac Voltage Controller dapat dihitung dengan persamaan sebagai berikut :

$$
V o=V s \sqrt{1-\frac{\alpha}{\pi}+\frac{\sin 2 \alpha}{2 \pi}}(3)
$$

Besarnya tegangan $V s=220$ volt dan bila nilai $\alpha=$ $40^{\circ}$ maka hasil perhitungan menjadi sebagai berikut :

$$
V o=220 \sqrt{1-\frac{40}{\pi}+\frac{\sin 2 \times 40}{2 \pi}}
$$




$$
=212,5835 \text { volt }
$$

Adapun prosentasi errortegangan keluaran rangkaian Ac to Ac Voltage Controllerdapat ditentukan dengan persamaan :

$$
\operatorname{error}(\%)=\frac{\text { Vteori }- \text { Vpraktek }}{\text { Vteori }} \times 100 \%
$$

Sehingga :

$$
\begin{aligned}
\operatorname{error}(\%)= & \frac{212,5835-201}{212,5835} \times 100 \% \\
& =5.449 \%
\end{aligned}
$$

Dengan menggunakan Oscilloscope dapat dilihat keluaran Ac to Ac Voltage Controller dengan beban heater pada sudut penyulutan (firing angle) $40^{\circ}$, seperti terlihat pada Gambar 4.1berikut ini :

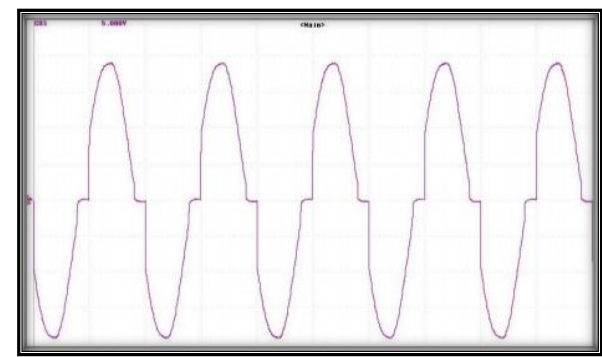

Gambar 4.1.Gelombang tegangan keluaran pada saat firing angle $40^{\circ}$

Bila diperhatikan grafik hasil pengujian rangkaian Ac to Ac Controller dapat dianalisa bahwa tegangan akan cenderung naik pada range firing angleantara $0^{\circ}$ sampai $90^{\circ}$. Pada saat firing angle $0^{\circ}$ tegangan akan naik sampai $220 \mathrm{~V}$ dan pada saat firing angle $160^{\circ}$ tegangan akan turun sampai pada 10V. Dengan demikian dari pengamatan data tersebut dapat disimpulkan bahwa untuk menurunkan teganganfiring angle yang harus diberikan adalah diatas $90^{\circ}$, Dari data tersebut dapat dikatakan pula bahwa semakin besar firing anglemaka penurunan tegangan akan semakin rendah.

Gambar 4.2.Grafik Perbandingan Tegangan Keluaran Terhadap Firing angle.

Besarnya firing angle dapat digunakan untuk mengatur besarnya arus dan tegangan keluaran yang diinginkan pada rangkaian $A C$ to $A C$ Voltage Controller.

\subsection{Respon Suhu pada Ruang Pengering Tanpa Kontrol}

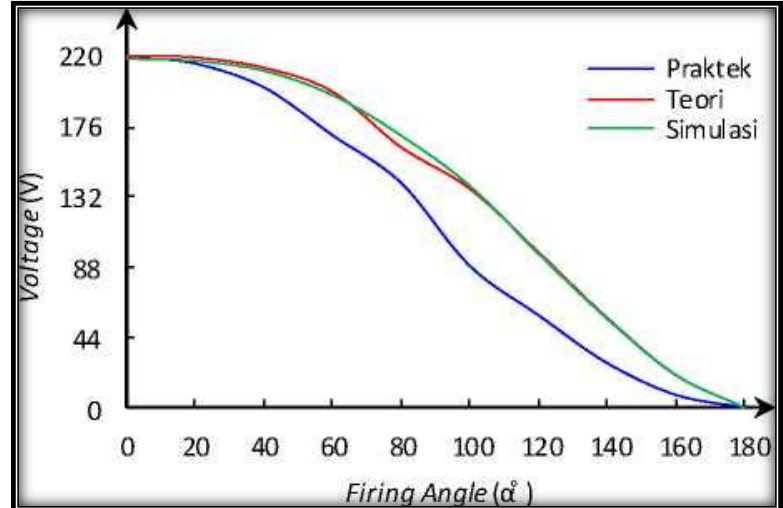

Pengujian respon suhu dilakukan pada saat alat terintegrasi tanpa control dan pada saat alat terintegrasi dengan control. Pengujian respon suhu tanpa kontrol adalah menguji alat terintegrasi tanpa control(open loop) yang terintegrasi dengan hardware ac to ac voltage controller, seperti terlihat pada Gambar 4.3 berikut :

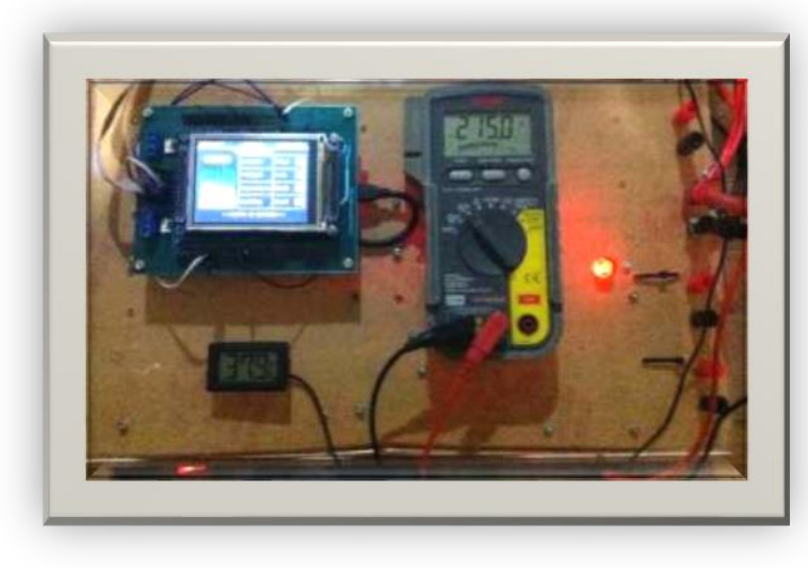

Gambar 4.3. Hardware rangkaian terintegrasi $A C$ to $A C$ Voltage Controller.

Terlihat pada Gambar 4.3 pada bagian atas merupakan interface, dimana terdiri dari LCD TFT sebagai monitoring suhu pada ruang pengering. Sedangkan bagian bawah terdapat rangkaian integrasi ac to ac voltage controller.

Hasil pengukuran tegangan keluaran nominal dari rangkaian $\mathrm{AC}$ to $\mathrm{AC}$ Voltage Controller pada saat firing angle sebesar $5^{0}$ diperlihatkan pada Gambar 4.1, dimana Nilai tegangan keluaran nominal untuk mensuplai beban heater dengan daya 1300 Watt adalah sebesar 215 Volt.

Adapun gambar selanjutnya, yaitu Gambar 4.4 adalah grafik respon suhu hasil pengujian $A C$ to $A C$ Voltage Controller tanpa kontrol (Open Loop) . Dari pengamatan pada grafik gambar tsb, menunjukan bahwa untuk mencapai suhu $70^{\circ} \mathrm{C}$ tanpa control dibutuhkan waktu sekitar 20 menit. 


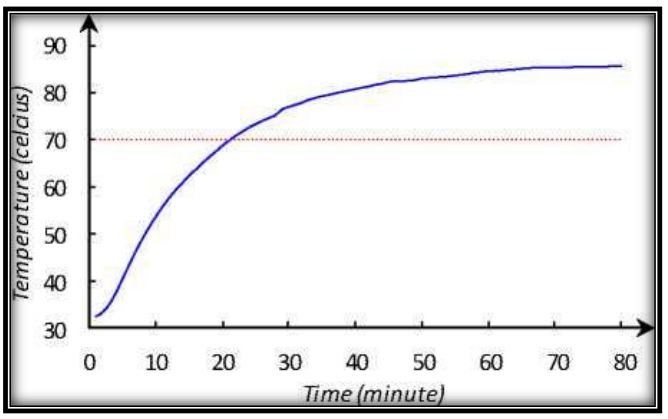

Gambar 4.4. Grafik respon suhu tanpa kontrol (Open Loop).

Dari data pada Grafik di atas juga dapat diamati bahwa kenaikan linier suhu terhadap waktu dari suhu awal ruang sebesar $33^{\circ} \mathrm{C}$ hingga $88^{\circ} \mathrm{C}$.

\section{2 .Respon Suhu pada Ruang Pengering dengan KontrolLogika Fuzzy}

Pada tahap pengujian respon suhu dengan kontrol logika fuzzy ini dilakukan alat dalam kondisi terintegrasi terkontrol (close loop), yang dilakukan 2 pengujian, yaitu ketika system pengering tanpa gangguan (data terlihat seperti pada grafik Gambar 4.5) dan juga ketika system pengering dengan gangguan (data terlihat seperti pada grafik Gambar 4.6).

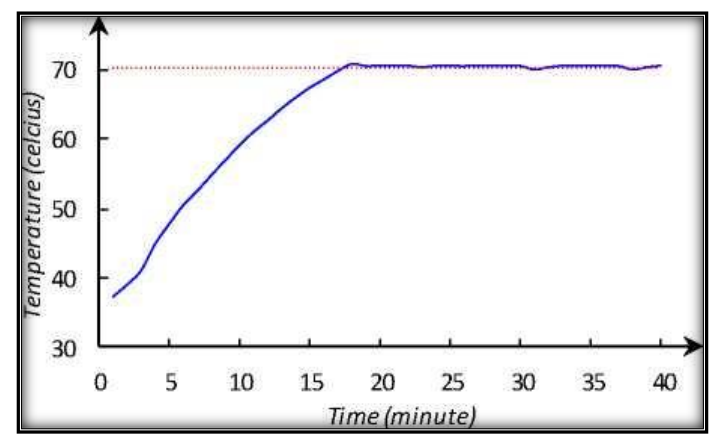

Gambar 4.5 Grafik Respon Suhu dengan Kontrol Logika Fuzzy tanpa Gangguan.

Dari Gambar 4.5 di atas terlihat bahwa system pengering dengan kontrol logika fuzzy tanpa gangguan tersebut butuh waktu 20 menit untuk mencapai suhu set point yaitu $70^{\circ} \mathrm{C}$. Sedangkan nilai steady state rata-rata nya sebesar $70.5^{\circ} \mathrm{C}$ dan nilai range steady state respon suhu menggunakan kontrol logika fuzzy antara $70,05^{\circ} \mathrm{C}-70,90^{\circ} \mathrm{C}$.
Adapun grafik pada Gambar 4.6 menunjukkan respon suhu menggunakan kontrol logika fuzzy terhadap gangguan. Hasil pengamatan : pada menit 29 respon suhu mendapatkan gangguan selama 1 menit pada menit ke 30 , suhu turun menjadi $64^{\circ} \mathrm{C}$ dan pelanpelan naik kembali menuju set point (yaitu $70^{\circ} \mathrm{C}$ ) pada menit ke 35 . Kondisi ini menujukkan bahwa kontrol logika fuzzy yang digunakan bekerja sesuai dengan yang diinginkan/perencanaan karena ketika diberi gangguan suhu turun tetapi tidak lama kemudian suhu kembali ke suhu set point.

Gambar 4.6 Grafik Respon Suhu dengan Kontrol Logika Fuzzy dengan Gangguan.

\section{Kesimpulan}

Dari hasil pengambilan data pada beberapa percobaan dan pengujian dapat disimpulkan antara lain adalah :

1. Rangkaian $\mathrm{AC}$ to $\mathrm{AC}$ Voltage Controller, yang memiliikpquegutêgan keluaran nominal

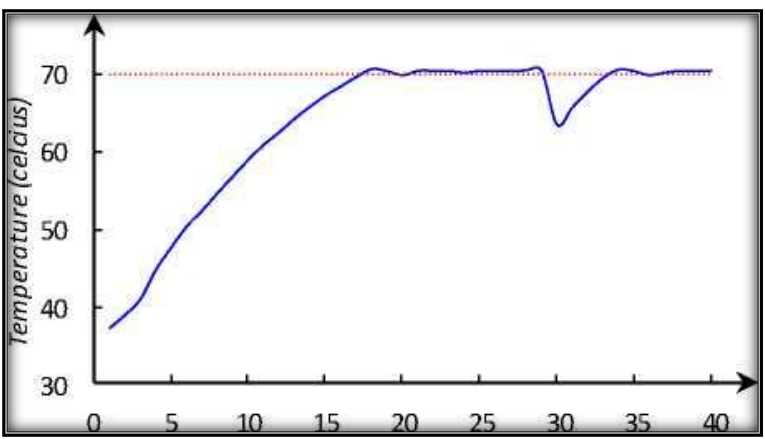

215 volt untuk mensuplai heater. Ketika firing angle $40^{\circ}$, sedangkan prosentase error tegangan keluaran AC to AC Voltage Controller relative kecil yaitu adalah 5,449 $\%$.

2. Hasil uji rangkian Ac to Ac Controller yang cukup bagus tersebut berdampak bagus pula pada sistem kontrol suhu dengan logika fuzzy pada pengering irisan kripik singkong dalam mempertahankan suhu sesuai dengan nilai set point. Hal ini disimpulkan berdasarkan data a.l : range steady state, yaitu antara suhu $70,05^{\circ} \mathrm{C}$ $70,90^{\circ} \mathrm{C}$, dengan nilai steady state rata rata $70,5^{\circ} \mathrm{C}$

3. Dilihat dari segi waktu pencapaian set point , control suhu dengan logika fuzzy ini juga lebih cepat. Berdasar data pada pengeringan awal, respon suhu untuk menuju set point membutuhkan waktu 20 menit. Dan ketika respon suhu dalam keadaan steady state, lalu mendapatkan 
gangguan, suhu turun menjadi $64^{\circ} \mathrm{C}$ dan kembali menuju set point $70^{\circ} \mathrm{C}$ dalam durasi waktu 6 menit.

4. Selain dari apa yang disebutkan di atas, hasil produk pengering irisan kripik singkong ini lebih hygiene karena tempat pengeringnya bersih, tertutup dan lebih cepat shg menghindarkan dari tumbuhnya jamur.

5. Karena sistem pengeringan irisan keripik singkong dengan kontrol logika fuzzy ini dalam ruang yang bersih, tertutup dan temperatur yang stabil sehingga proses pengeringan menjadi relatif lebih cepat kering. Hal ini dapat mengurangi potensi tumbuhnya jamur, tidak berbau dan tampilan lebih bersih/menarik, lebih hygiene. Dengan demikia kripik singkog hasil pengeringan system ini menjadi lebih disukai oleh konsumen sehingga nilai jualnya menjadi meningkat.

\section{Daftar Pustaka}

Pada teks, dafar pustaka harus disitasi dengan menuliskan no urut daftar pustaka

Contoh penulisan daftar pustaka :

[1] C. C. Lee. -Fuzzy logic in control systems: Fuzzy logic controller- part 1,1 IEEE trans. Syst., Man, Cybern., Vol.20, pp. 404-418, 1990.

[2] K. S. Rattan and G. S. Sandhu, -Analysis and design of proportional plus derivative fuzzy logic controller, Proc. National Aeronautics and Electronics Conference, Dayton, 1996.

[3] M. Sugeno, Ed.: Industrial Applications of Fuzzy Control, North- Holland (1985)

[4] Cheno-Jian Lin, - Temperature control using neurofuzzy controllers with compensatory operations and wavelet neural networks! Journal of Intelligent \& Fuzzy Systems 17, 2006.

[5] Koerniawan.A .2009 . "Rancang Bangun Rotary Dryer Sebagai Pengering Padi Berbasis Mikrokontroller". Jurusan Teknik Elektro Industri, Politeknik Elektronika Negeri Surabaya.

[6] P Singhalai. D.N Shah, B Patel,'Temperature Control Using Fuzzy Logic",. International Journal of Instrumentation and Control Systems (IJICS) Vol.4, No.1, January 2014,.Departemen of Instrumentation and Control, Sarvajanik College of Engineering and Technology Surat, Gujarat, India. 